\title{
Em busca da luz: notas sobre o Recital de Poesía al servicio de la verdad e a poética de León Felipe
}

\author{
Sonia Miceli \\ Universidade de Lisboa - Centro de Estudos Comparatistas,Portugal \\ soniamiceli@campus.ul.pt \\ https://orcid.org/0000-0002-4973-5038
}

Recibido: 1 de agosto de 2019

Aceptado: 20 de setiembre de 2019

Resumo: O ponto de partida deste artigo é um acontecimento ocorrido a 27 de julho de 1947 em Buenos Aires, a Festa da Poesia, no âmbito da qual teve lugar o Recital de Poesía al servicio de la verdad. Neste evento, participaram vários poetas espanhóis exilados e hispano-americanos, todos apoiantes da causa republicana e da luta antifascista. Entre eles, encontrava-se León Felipe, cuja obra e percurso biográfico são, sem dúvida, menos conhecidos que os de outros participantes - como Rafael Alberti ou Pablo Neruda. Por esta razão, são aqui examinados alguns aspetos da sua poética, com o objetivo de identificar figuras e temáticas recorrentes. Tomando como referência uma das obras principais do poeta, Ganarás la luz (1943), abordam-se a profunda ligação entre poesia e biografia, a figura do vento e o processo de reescrita permanente.

Palavras-chave: Festa da Poesia; Buenos Aires; poetas exilados; León Felipe; poesia espanhola; Geração de 27.

\section{In search of light: notes on the Recital de Poesía al servicio de la verdad and León Felipe's poetics}

Abstract: The starting point for this paper is an event which happened on July 27 , 1947 in Buenos Aires, the Poetry Festival. Within this festival, the Recital de Poesía al servicio de la verdad took place. Several exiled Spanish and Hispanoamerican poets who supported the republican cause and the antifascist fight took part in it. Among them, there was León Felipe, whose work and biographical trajectory are undoubtedly less known than other participants' - like Rafael Alberti or Pablo Neruda. For this reason, I examine here some aspects of his poetics, aiming at identifying recurrent images and topics. Taking as reference one of his

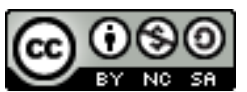

La Revista Estudios es editada por la Universidad de Costa Rica y se distribuye bajo una Licencia Creative Commons Atribución-NoComercial-CompartirIgual 3.0 Costa Rica. Para más información envíe un mensaje a 


\section{Dossier: Poesía, armonía y conflictos: ayer y hoy}

main works, Ganarás la luz (1943), I approach the deep relationship between poetry and biography, the image of wind and the process of permanent rewriting.

Key-words: Poetry Festival; Buenos Aires; exiled poets; León Felipe; spanish poetry; Generation of '27.

A 27 de julho de 1947, o panorama artístico e cultural da cidade de Buenos Aires foi marcado por um evento que reuniu algumas entre as mais relevantes vozes das letras hispânicas: a Festa da Poesia. Às mais importantes personalidades do exílio espanhol republicano, espalhadas pela América latina, sobretudo pela Argentina e pelo México, entre as quais se destaca o casal Rafael Alberti e María Teresa León, juntaram-se figuras de relevo, tais como Pablo Neruda e Nicolás Guillén, que vinham apoiar a causa republicana, entendida como parte de uma luta maior, popular e internacional, contra todo tipo de opressão. Neste sentido, compreende-se a presença de uma personagem como Guillén, membro do Partido Socialista Popular cubano, que tinha estado, tal como Neruda, em Espanha, na altura da guerra civil. Da mesma forma que outros poetas, Guillén chegou a Argentina alguns meses antes da Festa da Poesia, e viajou pelo país - e para o vizinho Uruguai - para ler poemas e dar palestras, cuja temática dominante era a ligação entre poesia e luta social, em especial, a luta dos negros nas Américas. Assim, pronunciou uma conferência intitulada "Presencia negra en la poesía cubana" e lançou uma campanha de apoio ao jornalista norte-americano Louis Lautier, vítima de discriminação racial no seu país.

A data escolhida para a organização do evento não foi casual. Por um lado, cumpriam-se onze anos desde o golpe militar que dera início à guerra civil, a 18 de julho de 1936; por outro lado, poetas e intelectuais queriam manifestar o seu profundo dissenso em relação à crescente aproximação entre Argentina e Espanha, cujos momentos marcantes foram: o reconhecimento do novo governo espanhol por parte da Argentina em 1939; a votação da Argentina contra a 


\section{Dossier: Poesía, armonía y conflictos: ayer y hoy}

exclusão de Espanha dos foros internacionais, recomendada pela ONU, em 1945; a viagem de Eva Perón ao país ibérico, em junho de 1947. Resultado desta política de cada vez maior aproximação seria o Protocolo Franco-Perón, um importante acordo comercial assinado no ano seguinte (Rein, 1990).

Este contexto explica a hostilidade inicial do governo argentino, que, instado pela embaixada espanhola a impedir o evento, só não o fez, devido à dimensão que este tinha adquirido, em razão da adesão de tantas e tão destacadas personalidades. Assim, acabou por autorizá-lo, desde que não se tratassem questões políticas. A imprensa portenha empenhou-se igualmente em divulgá-lo e louvá-lo, com a óbvia exceção dos jornais ligados ao governo, que denunciavam justamente o seu marcado cariz político antiperonista. Contudo, a maioria dos meios de comunicação terá manifestado o seu pleno apoio, contribuindo para que o Teatro Bambalinas, esse domingo, esgotasse rapidamente a sua lotação máxima, enchendo a multidão as ruas em volta.

Lamentavelmente, não há - ou, pelo menos, não consegui encontrar registos detalhados do recital, não tendo sido possível identificar os textos apresentados pelos poetas que nele participaram. Ainda assim, no mês de abril de 2017, um conjunto de investigadores - entre os quais me encontrava -, coordenados pela Professora Isabel Araújo Branco, apresentou um espetáculo com o mesmo título na Casa da América Latina, em Lisboa (Portugal), no âmbito da programação de Lisboa Capital Ibero-Americana da Cultura. Nessa ocasião, optámos por selecionar um conjunto de textos dos poetas mais destacados que tomaram parte no evento, a saber, Rafael Alberti, León Felipe, Nicolás Guillén e Pablo Neruda. O critério para a seleção dos textos foi temático - deveriam falar da paz e da guerra - e cronológico, privilegiando-se as obras publicadas nos anos imediatamente anteriores e posteriores a 1947.

No caso de León Felipe, provavelmente o menos conhecido e reconhecido entre os quatro, o livro do qual foram retirados os textos selecionados foi Ganarás

\section{(c) (†) (9)}

La Revista Estudios es editada por la Universidad de Costa Rica y se distribuye bajo una Licencia Creative Commons Atribución-NoComercial-CompartirIgual 3.0 Costa Rica. Para más información envíe un mensaje a 


\section{Dossier: Poesía, armonía y conflictos: ayer y hoy}

la luz, de 1943. A suposição de que desse volume terão sido extraídos os textos declamados na Festa encontra confirmação num artigo publicado a 11 de julho de 1947 no semanário uruguaio En Marcha, assinado pelo crítico e ensaísta Emir Rodríguez Monegal. Este, num texto dedicado ao poeta, relatava uma conferência por ele dada em Montevideo na semana anterior, na qual lera poemas do livro de 43, sublinhando o autor a dimensão performativa do acontecimento, ao revelar que "León Felipe no leyó los poemas en el orden en que los ofrece el libro, sino que los orquestó nuevamente, enriqueciéndolos por un montaje diferente. $Y$ en algunos casos hasta los modificó" (p. 15). Encontramos, assim, um elemento decisivo no projeto poético de Felipe: o contínuo fazer-se e desfazer-se dessa obra, marcado pela repetição e a constante modificação e recuperação de temas, versos, imagens. Figura deste movimento constante, o Vento, que volta obsessivamente ao longo de toda a sua obra.

Embora mais velho - nasceu em 1884 - que Alberti, García Lorca e a maioria dos poetas do grupo que se costuma designar por Geração de 27, é a este grupo que tem sido, em parte, associado León Felipe, e com este partilhou a adesão à causa republicana e a conseguinte condenação ao exílio, condição em que viveu até ao fim dos seus dias. Autor de um livro intitulado Versos y oraciones del caminante, de 1920, que constitui a sua estreia poética, León Felipe, muito antes de passar pela experiência do exílio político, incorpora as temáticas da errância e do desenraizamento na sua poesia, que se configura, desde cedo, como marcadamente biográfica: "La poesía se apoya en la biografía. Es biografía hasta que se hace destino y entra a formar parte de la gran canción del destino del hombre" (2006, p. 91), escreve em Ganarás la luz, cujo subtítulo reza, aliás, "Biografía, poesía y destino". Próxima da poesia pós-simbolista e das vanguardas que surgiam como reação à poesia dita pura, desligada do mundo concreto, de raiz modernista, a poesia de León Felipe - que, na década de 30, escrevia que "todo lo que hay en el mundo es [...] valedero para entrar en un poema. Todo.

La Revista Estudios es editada por la Universidad de Costa Rica y se distribuye bajo una Licencia Creative Commons Atribución-NoComercial-CompartirIgual 3.0 Costa Rica. Para más información envíe un mensaje a 


\section{Dossier: Poesía, armonía y conflictos: ayer y hoy}

Hasta lo literario, como arda y se queme" (citado en Frau, 2002, p. 94) - é impregnada de humanidade e de uma profunda espiritualidade, tendo o poeta uma responsabilidade social e uma função profética que, naturalmente, se acentuaram com a experiência da guerra, do exílio e do empenho antifascista.

O envolvimento com a causa republicana e o exílio num país latinoamericano, mais concretamente, no México, país que acolheu milhares de exilados republicanos e onde já vivera antes da guerra, contribuem para explicar a ligação que León Felipe manteve, ainda que à distância, com um poeta como Rafael Alberti, que voltará a encontrar em Buenos Aires, precisamente por ocasião da Festa da poesia. E, num artigo de homenagem ao amigo já falecido, publicado no El País em maio de 1976, Alberti recorda esse derradeiro encontro com estas palavras:

La tercera vez encontré a León Felipe en Buenos Aires, y al cabo de unos años de no verlo, pero de oírlo, sin embargo. Cuando los españoles del éxodo nos encontramos, y más cuando uno de ellos se llama León Felipe, es como si chocaran, si se unieran pedazos de tierra vagabundos, trozos vivientes de una entraña lanzados a lo alto, dispersos por una mala tromba.

Allí me tropezaba con España. Allí chocaba. Allí me daba contra alguien muy vivo, muy sangrante, muy desesperado, muy animoso.

Venía ganándose la luz mientras ya otros se habían ganado definitivamente la sombra. Nos afirmó entonces León cómo el cielo le hizo que él fuera Jonás, tal vez fuera Job, nadie, o el viento. ( $A$ León Felipe, en su homenaje, párr. 9-11).

Poeta do sofrimento e da responsabilidade - simbolizados pelas figuras bíblicas aqui evocadas, além de outras míticas, como, por exemplo, a de Prometeu -, León Felipe escolhe, como vimos, o Vento como figura do movimento - do Espírito ou da História, segundo os críticos - que leva o poeta a cumprir a sua missão e, com isso, a ganhar a luz.

\section{(c) (i) (2)}

La Revista Estudios es editada por la Universidad de Costa Rica y se distribuye bajo una Licencia Creative Commons Atribución-NoComercial-CompartirIgual 3.0 Costa Rica. Para más información envíe un mensaje a 


\section{Dossier: Poesía, armonía y conflictos: ayer y hoy}

Livro extenso e complexo, Ganarás la luz expõe, logo no Prólogo, o projeto que o justifica: responder à pergunta “¿Quién soy yo?”, que devia ser, aliás, o título do próprio volume, substituído por conselho do amigo poeta Juan Larrea. Através do caminho traçado pelo livro, o poeta procura, portanto, encontrar o seu nome, isto é, a sua voz. E este projeto, perseguido por alguém que estava, na altura, com quase sessenta anos de idade, contando com mais de duas décadas de obra poética já publicada, traduz-se num gesto significativo: o da criação de uma antologia, que se desdobra numa reescrita obsessiva e permanente. Ora, o que me importa realçar é que o trabalho do antologista não é entendido, aqui, como um trabalho apenas individual; implica, pelo contrário, um processo coletivo, de legitimação e reconhecimento - é isto que permitirá ao poeta descobrir o seu nome: "Les contaré mi vida a los hombres para que ellos me digan quién soy" (Felipe, 2006, p. 95), escreve, enquanto apresenta o livro - ou melhor, o seu projeto - como uma "autobiografía poemática" (p. 104). Assim, o livro procura construir uma comunidade que batize, num certo sentido, o poeta: o nome dele depende justamente disso e a poesia, de projeto individual, converte-se em projeto coletivo, universal. E poderemos atribuir a esta afirmação não apenas um valor simbólico, mas mesmo literal: assim, a exortação que se encontra em "La poesía está en la sombra", de que reproduzo alguns excertos (pp.123-124), ecoará num texto de caráter testemunhal, publicado na revista uruguaia Clinamen, em maio de 1947. Veja-se:

Y digo que la Poesía está en la sombra, en la sombra del mundo donde el hombre ciego se revuelve y grita... [...]

El poema es un grito en la sombra como el salmo, hoy no es más que un salmo en la sombra, y también una tea encendida en la niebla.

La sombra es tuya y mía y hoy más negra que nunca.

La sombra es de todos... 


\section{Dossier: Poesía, armonía y conflictos: ayer y hoy}

y el salmo y el grito también.

$Y$ yo, el hombre, ¿ya no puedo gritar, ya no puedo llorar?

[...]

La Poesía... ¿es vuestra solamente?

Mientras haya una sombra en el mundo, la Poesía es mía y de Job y de todos los hombres de la sombra.

Mañana será de luz, pero hoy la Poesía es de la sombra.

[...]

Para que grite conmigo busco yo al hombre y le digo:

La Poesía es un canto en la sombra, canta conmigo;

La Poesía es un grito en la sombra, grita conmigo;

canta, canta y grita... igrita!

No texto publicado em Clinamen, Felipe (1947) expõe considerações semelhantes e propõe compor uma "Antología poética y maldita", que seria

española... hispanoamericana... continental... universal. Cada pueblo debe contribuir con sus mejores poetas a una antología de esta clase, a una antología donde se recojan los versos más negros y desesperados [...], como documento poético terrible y desconsolador, donde la voz de la tierra ultrajada se levanta insconsciente y blasfematoria a dar testimonio de la sombra (p. 12).

Fica claro, portanto, que a tournée sul-americana, da qual a estadia em Buenos Aires, com a participação na Festa da Poesia, fez parte, serviu o propósito de estreitar os laços com a comunidade de poetas e público que apoiavam a causa republicana, permitindo ao poeta encontrar o seu caminho em direção à luz.

Esta criação de uma comunidade poética universal passa pelo estabelecimento de uma nova relação com a origem - Espanha -, trabalhada ao longo do livro e que se traduz na sua reconstrução. Assim, em "Poética de la llama", lemos:

\section{(C) $(00$}

La Revista Estudios es editada por la Universidad de Costa Rica y se distribuye bajo una Licencia Creative Commons Atribución-NoComercial-CompartirIgual 3.0 Costa Rica. Para más información envíe un mensaje a 


\section{Dossier: Poesía, armonía y conflictos: ayer y hoy}

Lo que fue ayer un toro ya no es más que una constelación. De aquí nací yo. Aqui estuvo mi origen. $\mathrm{Y}$ aquí está ahora mi destino: con signos poéticos escrito en la sangre del mundo y en la cartografía de los cielos.

No lloro por mi patria perdida. Todo se traslada y se levanta. La metáfora se mueve y asciende por una escala de luz. (Felipe, 2006, p. 160)

E o país perdido - ao qual León Felipe, falecido em 1968, nunca mais voltou sofre, dentro do percurso traçado pelo livro, um processo de assimilação por essa constelação maior, como mostram os poemas irmãos "Hay dos Españas" e "Los dos mundos", em que a mesma estrutura dual é aplicada, no primeiro, a um caso específico - o da Espanha republicana vs. a Espanha fascista -, no segundo, a um conjunto de conceitos, que se prestam a uma leitura a um tempo política, literária e metafísica. Ambos os poemas, aliás, haviam sido publicados, tal como muitos outros de Ganarás la luz, em obras anteriores, sendo que, no caso de "Los dos mundos", este formava parte de uma versão do poema "La insignia", publicada em plena guerra civil e em que os dois mundos eram, ainda, as duas Espanhas. Veja-se a abertura do primeiro: "Hay dos Españas: la del soldado y la del poeta. La de la espada fratricida y la de la canción vagabunda. Hay dos Españas y una sola canción. Y ésta es la canción del poema vagabundo" (p. 112). Se, neste poema, Espanha e o poeta são as figuras dominantes - e o poeta levará com ele a canção, dela privando o soldado -, a revisitação deste tópico que se dá em "Los dos mundos" passa também pela construção de um novo olhar sobre o poeta, que perde o lugar de destaque que Ihe tinha sido atribuído, pois só "el hombre, el hombre heroico es lo que importa" (p. 172). E, no entanto, este poema está incluído na secção intitulada "Prometeo", que é justamente a mais intensamente metapoética do volume, uma vez que todos os seus textos contribuem para desenhar aquela que o autor denomina uma poética da chama. Assim, a referida desautorização da figura do poeta terá mais a ver com uma crítica aos poetas alienados - porque ausentes do poema - do que propriamente 


\section{Dossier: Poesía, armonía y conflictos: ayer y hoy}

à poesia tout court, nela, "el Poeta Prometeico trabaja con su sangre donde van disueltos los esfuerzos de todos estos poetas especializados" (p. 176). Dá-se, assim, a sobreposição do país de origem com o mundo, da poesia com a vida, do canto individual com o canto universal.

O exemplo do tratamento do tema "Espanha" enquadra-se, em suma, nessa poética da reescrita, em que a obra vai ganhando forma enquanto antologia, seja da produção do próprio, seja da de outrem, pois, como lemos em "¿Y si me llamase Prometeo?", "Si yo no puedo ser la justificación, la prolongación y la corrección de Whitman [...], la Poesía, toda la Poesía del mundo no es más que una canción paralítica" (p. 157). Assim, Ganarás la luz termina em aberto, sem que a resposta à interrogação inicial - “¿Quién soy yo?” - seja encontrada. Ou talvez justamente nessa ausência de resposta, nessa abertura marcada pela ação do Vento, que vai encerrar o último poema do livro, "Me voy porque la tierra y el pan y la luz ya no son míos" (p. 269), esteja o que o poeta, desde o princípio, procura. Pois, o poema final encerra uma sequência de poemas, que anunciam a partida do poeta, em permanente busca da luz. E essa busca dar-se-á no livro como na vida, na longa viagem sul-americana que, entre 1946 e 1948, levou León Filipe a visitar vários países da América latina, para cumprir a sua missão de poeta e profeta, em caminho, sempre.

\section{(c) (i) (2)}

La Revista Estudios es editada por la Universidad de Costa Rica y se distribuye bajo una Licencia Creative Commons Atribución-NoComercial-CompartirIgual 3.0 Costa Rica. Para más información envíe un mensaje a 
Dossier: Poesía, armonía y conflictos: ayer y hoy

\section{Bibliografia}

Alberti, R. (1976, mayo 4). A León Felipe, en su homenaje. El País. Recuperado de https://elpais.com/diario/1976/05/04/opinion/200008802 850215.html

Felipe, L. (2006). Ganarás la luz. Madrid: Catedra.

Felipe, L. (1947). El poeta maldito. Clinamen, 2(mayo-junio), pp. 11-14.

Frau, J. (2002). La teoría literaria de León Felipe. Sevilla: Secretariado de Publicaciones de la Universidad de Sevilla.

Llopis, E. (2013). Rafael Alberti: la deriva de un marinero en tierra argentina (19401963). Buenos Aires: Ediciones de Aquí a la vuelta y CCC.

Rein, R. (1990). El Pacto Perón-Franco: justificación ideológica y nacionalismo en Argentina. Estudios Interdisciplinarios de América Latina y el Caribe, 1(1). Recuperado de http://eial.tau.ac.il/index.php/eial/article/view/1313/1339

Rodríguez, E. M. (1947). "Tal vez se llame Jonás" (Glosas a León Felipe). En Marcha, 387, pp. 14-15.

Título en español: En busca de la luz: notas sobre el Recital de Poesía al servicio de la verdad y la poética de León Felipe

La Revista Estudios es editada por la Universidad de Costa Rica y se distribuye bajo una Licencia Creative Commons Atribución-NoComercial-CompartirIgual 3.0 Costa Rica. Para más información envíe un mensaje a 